\title{
Re-evaluating our approach to forest management planning: A complex journey
}

\author{
by Anne-Hélène Mathey ${ }^{1,2}$, Emina Krcmar ${ }^{1}$ and Ilan Vertinsky ${ }^{1}$
}

\begin{abstract}
The evolution of forest values from timber supply to ecological and social values has been leading to the redefinition of the Sustainable Forest Management (SFM) paradigm. In parallel, scientific knowledge is expanding and uncovering the interconnectedness of the various processes that support these values. We thus have many wishes and much knowledge but we have to ensure that we have the decision support tools that will pull them together to promote SFM. After a broad review of the evolution of decision support tools in forest management, this paper presents a case for more holistic numerical planning tools. To illustrate that such tools can be designed, we propose a simple decentralized approach. In this approach, a landscape management strategy evolves based on local decisions, integrating spatial and aspatial, multiperiod and period-specific goals. Such tools could become a useful platform for sustainable forest management planning.
\end{abstract}

Key words: decision support tools, sustainable forest management, evolution, holistic planning, complexity, cellular automata

\section{RÉSUMÉ}

L'évolution des valeurs forestières passant de l'approvisionnement en matière ligneuse aux valeurs écologiques et sociales entraîne une redéfinition du paradigme de l'aménagement forestier durable (AFD). Parallèlement, les connaissances scientifiques prennent de l'ampleur et dévoilent les liens entre les différents processus qui supportent ces valeurs. Nous avons en conséquence plusieurs souhaits à notre portée et détenons beaucoup de connaissances, mais est-ce que nous avons en main les outils d'aide à la décision qui permettraient de les rassembler pour promouvoir l'AFD ? À la suite d'une revue générale de l'évolution des outils d'aide à la décision en matière d'aménagement forestier, cet article fait état d'un exemple faisant appel à des outils d'aide à la décision plus holistiques. Pour démontrer que de tels outils peuvent être élaborés, nous proposons une simple approche décentralisée. Selon cette approche, une stratégie d'aménagement du territoire prend forme à partir des décisions locales et intègre les objectifs spatiaux et non spatiaux répartis sur plusieurs périodes ou spécifiques à une période donnée. De tels outils pourraient devenir une plateforme utile en matière de planification de l'aménagement forestier durable.

Mots clés : outils d'aide à la décision, aménagement forestier durable, évolution, planification holistique, complexité, automates cellulaires

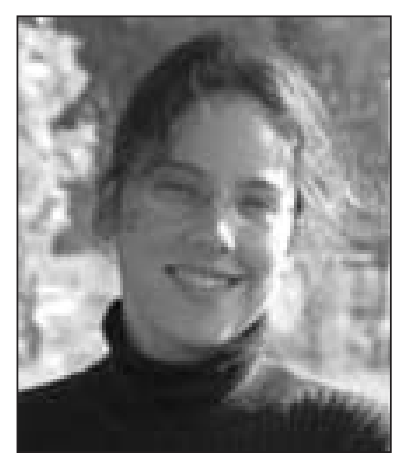

Anne-Hélène Mathey

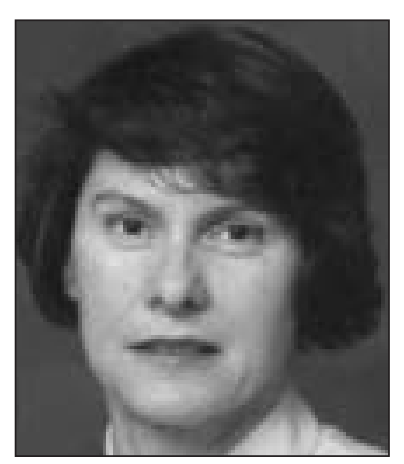

Emina Krcmar

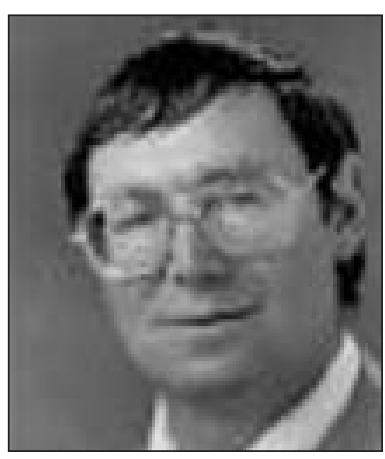

Ilan Vertinsky

\section{Introduction}

The process of decision-making in forest management describes the selection of one alternative course of action for a particular forest. Each course of action connects to a particular set of anticipated future forest conditions and it is the desirability associated with each set that drives the selection process. Planning is essentially the tool that links actions to outcomes and outcomes to desirability (Davis et al. 2001). Planning therefore requires knowledge of the environment and of the impacts of management actions. In addition, it also requires an acknowledgement that social preferences are at the core of how we define what constitutes a "desirable" outcome. The concept of "desired future forest," however, is not a static paradigm.

Between the 1920s and the 1990s alone, a period no longer than the length of a standard harvest rotation in the temper- 
ate latitudes, the perception of forests has broadened from a seemingly infinite resource basis and a focus on timber values to view them as a scarce source of multiple values (Agnoletti and Anderson 2000). Management has accordingly adjusted from sheer resource exploitation to sustained yield in the '50s and then to incorporation of other demands with multipleuse management by the end of the '60s. The concept of Sustainable Forest Management (SFM) appeared in the '90s and engendered such paradigms as "ecosystem management" and "integrated forest management." These paradigms emphasize the maintenance of ecological integrity of the forest ecosystem while generating desired services and products.

The first objective of this paper is to present a broad overview of how decision support tools have adapted to the new SFM requirements. To this end, we broadly examine the changes in conservation, social and economic demands on forest management and some parallel scientific developments. The second objective of this paper is to present an alternative planning tool as an example of a decision support methodology that is capable of acting as a platform for the holistic context of SFM.

\section{Environmental Sustainability}

In the 1960s, the alarm of scientists at the rate of species loss and the increasing public concern over environmental resources led to the rapid development of conservation biology (Meffe et al. 1997, Fiedler and Kareiva 1998) and eventually to official protection positions (UNCED 1992). The initial protection measures focused on species (e.g., USA Endangered Species Act); but since then it has become increasingly clear that species could not be protected without consideration for the underlying ecological processes that support their existence. As a result of the advances in such fields as community and landscape ecology, forests are now recognized as complex system; they are the product of a number of interacting ecological processes that occur at various temporal and spatial scales (Voller and Harrison 1998, Sherry and Johnson 1999). Along with an adapted management on the rest of the forest matrix, the design of particularly sized and shaped reserves with a distribution through space and time ensures conservation (Oliver 1999, Schwartz 1999, Shafer 2001).

Once the targets for conservation are identified in a particular area, coarse-filter strategies are often the approach of choice. This improves planning efficiency at the strategic level and avoids a complete species-by-species planning process. A coarse-filter approach is also proactive in limiting the potential for further species endangerment. Disturbance ecology and landscape ecology have developed an array of measures to qualify and monitor the environment spatial patterns (landscape ecology metrics). These metrics can be used to design reserve areas and adapted management practices. Ensuring that the requirements of conservation targets at finer scales are met constitutes the final step of any conservation strategy.

\section{Implications for forest planning}

The conservation goals of SFM require that the planning techniques developed for landscape ecology and conservation biology be integrated in forest planning. As a direct consequence, planning needs to be spatial to adequately model the different levels at which forestry practices can impact the landscape. This can also reduce issues such as road planning in sensitive ecosystems (stand-level) or fragmentation of oldgrowth forests (landscape-level). Temporal variations of physical patterns must also be measurable to compare them with natural disturbance cycles. In short, it must be possible to evaluate the degree to which conservation goals are met in the forest management plan.

\section{Social Sustainability}

Social acceptability towards forestry has had a powerful impact on forest management that reaches beyond conservation and can affect all forest operations. Some changes were the direct consequences of public lobbying against forest industry (court decisions, social actions by NGOs, media attention). Other changes were the indirect consequence of political choices, eventually expressed through government regulation or legislation (e.g., Forest Act in the US). These changes were evidence that social acceptability is essential to the success or failure of forest management strategies (Clawson 1975), and substantial research was initiated to clarify the social processes underlying forest management.

Social acceptability was found to relate to both the outcomes and the process of planning. However, acceptable outcomes are difficult to evaluate - there are usually multiple forest stakeholders with multiple value systems (Stankey and Clark 1992), which are not fixed but change depending on the spatial, cultural, institutional and temporal contexts (Berkes and Folke 1998). Regardless of outcome acceptability, forest management strategies may further be rejected on the basis of the planning process itself, and the lack of trust in the planning team (Shindler et al. 2002).

\section{Implications for forest planning}

It follows that SFM ideally encompasses the multiplicity of stakeholders and their values and should result from a consensus. This may involve re-evaluating planning as a continuous process where the planning team is able to elicit trust and to continue the relationship with stakeholders during plan implementation. In this context, the ability of decision support systems to generate optimal solutions is not as crucial as their capability in providing visualization of management alternatives as a basis for discussion.

\section{Economic Sustainability}

In the more specialized setting of economics, society also impacts forestry insofar as it affects the allocation of forest resources. This is exemplified by changes brought by the trend towards buying wood from certified forests. However, the social demand for specific forest products is only one of the factors that have modified the economic situation of the forestry sector over the past decades. Technological advances, economic recessions, globalization of the industry and changing consumer demographics have all contributed to the industry producing only what it could sell (Porter and Martin 2000, Cohen and Kozak 2002). The utilization of species previously considered worthless, the emergence of new suppliers and new markets, or trade disputes are other examples of the changing economic context.

Paralleling these changes, a number of new economic concepts have been developed that may lead to a redefinition of forest economics models - the role of institutions, non-stat- 
ic preferences, multiple levels of utility, co-evolution between natural and social systems or the effect of uncertainty on maximization (Jacobs 1991, Kant 2003).

\section{Implications for forest planning}

The necessity to tighten the connection between the elements of the value chain, from forest management to wood processing to markets, means that the decision support system must be amenable to scenarios analyses across this chain. Platforms that can accommodate alternative market outlooks could enhance the ability of forest management to satisfy the economic goals of SFM. Decision support tools must further be able to model the co-evolution between natural and economic processes in order to propose more effective plans. Incorporation of dynamic parameters is useful not only to reflect alternative market scenarios but also to integrate changing social preferences.

\section{Decision Support Tools and SFM Planning}

With current management considering more than just timber production, the traditional use of stand-level cost-benefit type analyses in forest management planning (Bare et al. 1984) has become obsolete (Reed 2000). After the inception of environmental concerns, these analyses were superseded by top-down planning models associated with centralized procedures such as mathematical programming (Weintraub and Bare 1996, Martell et al. 1998). Top-down planning models address the aggregate objectives of forest management efficiently (e.g., harvest flow). However they do so without explicit considerations of the system's constituent elements. Top-down procedures therefore imply a strong understanding of the relationships between local processes and global properties. Too many local exceptions may compromise these relationships (e.g., stream buffers, traps, private cottages, or culturally sensitive areas) to the extent that the strategic plan thus generated is unachievable (McDill 1992).

Spatial planning schemes were consequently introduced; however, when combined with centralized approaches, the size of the resulting combinatorial problem can become an issue (Martell et al. 1998). Hierarchical modeling (Weintraub and Cholaky 1991) and the use heuristics (Nelson 2003) help resolve this problem. Progress has since been made towards integrating multiple goals at various scales. Yet, decision support tools rarely simultaneously address all the scales and processes relevant to forest management goals. For instance, it is possible, albeit difficult, to formulate spatial goals such as size, shape and distribution of reserve clusters (Ananda and Herath 2003, Stewart et al. 2004, Venema et al. 2005), to integrate multiple stakeholders (Stewart et al. 2004) or to generate visual quality scenarios (Sheppard et al. 2004). However, few planning tools address scheduling of actions and fulfill both aspatial goals (e.g., harvest or cash flows) and spatial goals such as dynamic and contiguous reserve areas on the landbase.

It has been suggested that decentralized bottom-up approaches may better capture the interconnectedness between local processes and decisions and regional ones (Strange et al. 2002). We present a methodology combining such an approach with a co-evolutionary scheme to simultaneously address scheduling of forestry operations while considering volume flow, net present value, dynamic parameters (social preference or market outlooks) and clustering of conservation areas.

\section{Evolutionary Forest Management Planning Problem statement}

A forest plan, over a given planning horizon, consists of a prescribed schedule of treatments. There is one schedule for each stand that comprises the forest. In this paper, we present an iterative algorithm that begins with an initial plan and, with each iteration, attempts to improve the overall forest plan. The scheme is based on the notion of cellular automata (CA). A cellular automaton is an abstract machine with a state selected from a finite set of states and a set of transition rules. Applied at discrete time intervals, they determine the automaton's subsequent states based on the cell's own state and the states of its neighbours (Toffoli and Margolus 1987). CA models are generally constructed as a collection of cells that form a lattice. The decentralized transition rules and the spatial interdependence of the lattice cells account for CA's self-organization and scale-integration capabilities. These capabilities make CA an efficient tool in modeling complex systems: urban development, population dynamics, vegetation succession, forest fires, spatial economics and, of particular interest, afforestation decisions (Strange et al. 2002). We propose that CA may further be used for scheduling of forest management and conservation of old forest.

\section{Methods}

A forest plan can be represented by a CA model by treating each stand (represented by a raster cell) as a cellular automaton. The state of a stand is one of the many alternative schedules of treatments that could be applied to the stand. Examples of states range from the no-treatment state with no actions scheduled for the length of the planning horizon to the harvest of the stand at the beginning of the planning horizon and again at the end of the planning horizon. Each alternative stand treatment schedule is an alternative state. A forest plan thus consists of the assignment of a management state to every cell.

The neighbours of each stand could be those stands that border or that are within a certain geometric distance from the stand. A state transition function would determine the new (possibly the same) treatment schedule for a stand as a function of the current forest plan as it applies to the stand and its neighbours. The forest plan evolves by iteratively generating new stand schedules (states) using the state transition function in individual stands. In our scheme, the state transition function chooses the stand schedule that maximizes an objective function.

Formally, an individual lattice point or stand, $l$, is a member of the set of all stands $L$ which represents the forest. We let $N(l)$ represent the set of neighbours of the stand $l$. Then, $n \epsilon$ $N(l)$ implies that the stand $n$ is a neighbour of the stand $l$. Each stand $l$ is in a particular state $s(l)$ where the state represents a particular schedule of stand level treatments. A forest plan will be represented by the set $C=\{s(l) \mid l \in L\}$.

A stand's state is evaluated as a weighted average of two components. We refer to the first component as the locationindependent or aspatial component. It represents the expected utility generated by the stand state/schedule that is independent of the states of neighbouring stands. Contributions 


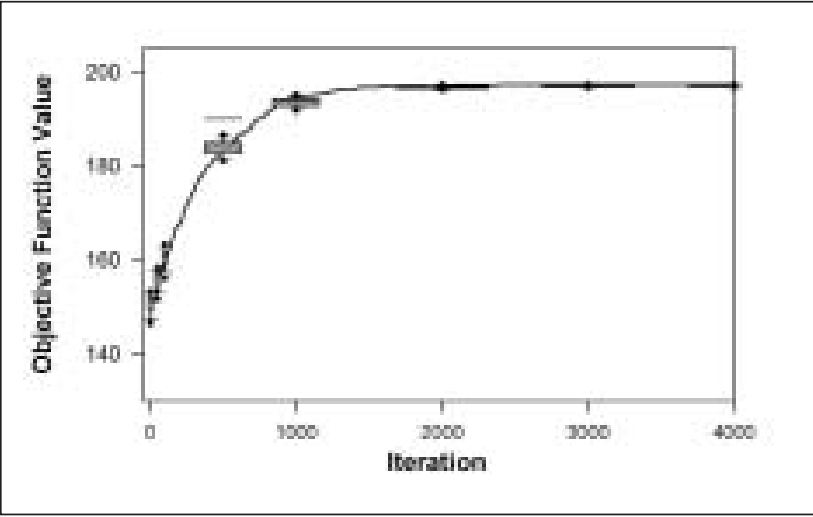

Fig. 1. Progress of the objective function value through iterations. The line represents the progress for one run and the box plot represents the spread of the objective function value at iterations $1,50,100,500,1000,2000,3000$, and 4000.

to this component could be the net present value or the volume flow of scheduled harvests.

The second component of value is the synergistic expected utility associated with a schedule that results from the spatial context of the neighbouring schedules. One contribution to this component could be an old growth value that is enhanced if neighbouring stands are simultaneously old. Similarly, adjacent cut blocks could decrease harvesting and treatment costs and induce scale economies.

A stand's value is computed as:

$$
v(s(l), l)=w_{h} h v(s(l), l)+w_{o} o v(s(l), l)
$$

where

$s(l) \quad$ is the stand's schedule

$l \quad$ identifies the individual stand

$w_{h}, w_{o}$ are weighting factors (proportion) for the relative contributions of the spatial and aspatial contributions to the total stand value

$h v(s(l), l)$ is the local value of a stand $l$ with schedule $s$ (e.g., the "harvest" value). The stand $l$ contributes to the local value through stand specific attributes such as its initial inventory, site quality, and distance from processing facilities

$o v(s(l), l)$ is the spatial/context determined value of a stand 1 with a schedule s (e.g., the "old growth" value). Again the value may depend on stand specific attributes.

A configuration's value is thus:

[2]

$$
\begin{aligned}
V(C) & =\sum_{k=1} v(s(l), l) \\
& -\sum_{\ell=I}\left[w_{h} h v(s(l), l)+w_{0} \operatorname{ov}(s(l), l)\right]
\end{aligned}
$$

The above system becomes a CA model with the addition of a state transition function and a state updating procedure. The state transition function selects as the next state/schedule, the schedule that maximizes (the subscript associated with a schedule indexes iterations in the cellular automata updating):

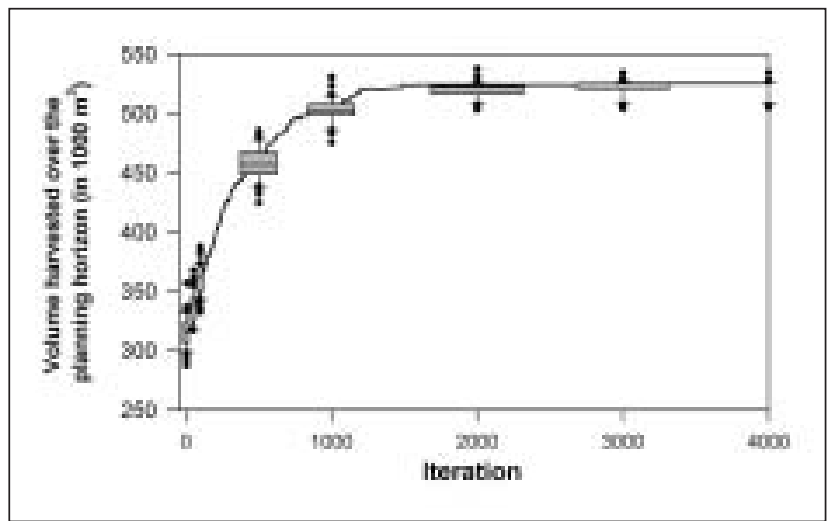

Fig. 2. Volume flow over the planning horizon through iterations. The line represents the progress for one run and the box plot represents the spread of the objective function value at iterations $1,50,100,500,1000,2000,3000$, and 4000.

$$
v\left(s_{i+1}(l), l\right)=\max _{s} v(s(l), l)
$$

For each iteration, the initial iterative scheme consists of a probabilistic updating procedure where the state transition function is applied to randomly selected cells. This updating procedure may not converge to a stationary configuration. Improving the value for one stand may lower the value of neighbouring stands which can generate an oscillation of "improvements" going back and forth between neighbouring stands.

The above scheme can be guaranteed to converge by modifying the updating procedure and introducing asynchronous updating. In each iteration, we thus generate a random order for cell updating. The schedule of a selected cell will only be changed if the value of the stand improves. As soon as an update occurs, i.e., the cell's new state is different from the cell current state, a new iteration starts. This process allows other cells to experience the new environment and to react to it, hence co-evolving. If the cell's state is not updated because there are no better states, the next cell's state in the order is considered for update. The iterative process essentially stops when all cells of the random-order list generated in one iteration are checked without any update occurring.

\section{Sample case}

The test area is located in the boreal forest of northern Ontario (Canada). It was chosen for the quality of its inventory information and the range of forest managements practised there. It is approximately 4374 ha represented by an 18 $\times 27$ grid of square cells where each cell is 9 ha. To simplify the computation of the forest management problem, the number of strategies was reduced by considering only combinations of different silvicultural regimes of predefined treatments sequences with harvest schedules. Silvicultural regimes considered include "no-management," extensive, basic evenaged, intensive even-aged and, elite even-aged regime.

In this sample case, the objectives are reduced to one aspatial and one spatial goal with two different time perspectives. The value consists of a weighted average of the harvest volume generated over the entire planning horizon and of the number and compactness of old forest areas in each planning 


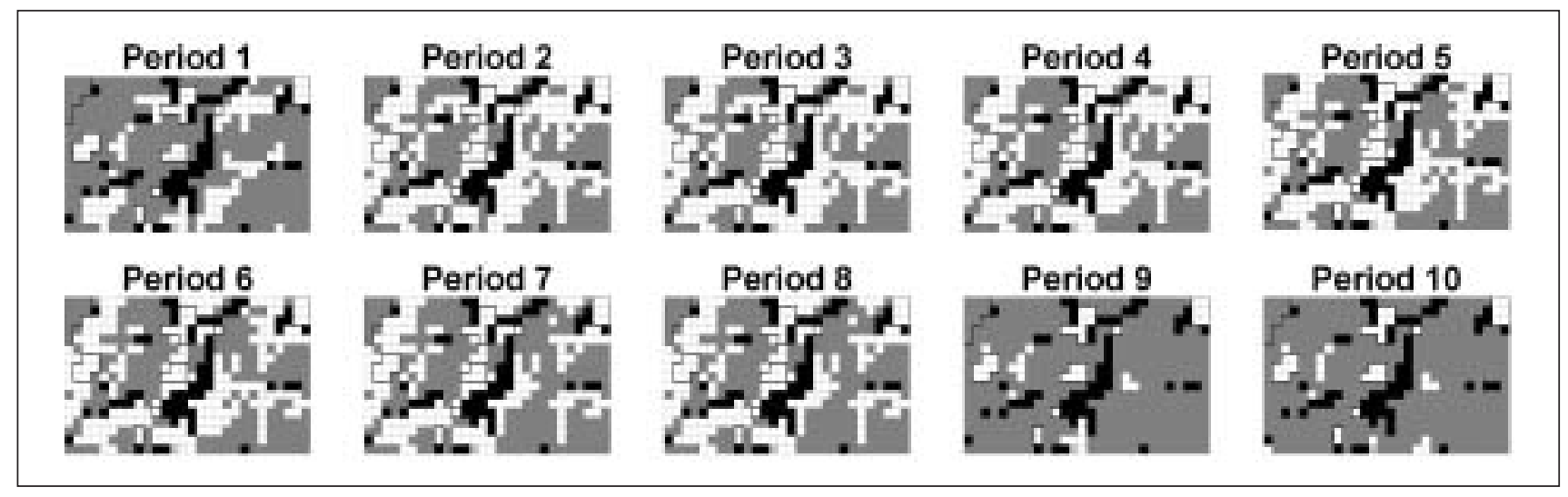

Fig. 3. Final solution obtained for a simulation run with approximately 4000 iterations. Black lines delimitate areas that are not under management. Light grey cells represent lakes. Dark grey cells are old forest areas and white cells are younger forests.

period. There are no constraints. The weights associated with each value are assumed to remain constant.

The model code is built upon the ESRI ARC/INFO software and consists of a number of files coded in Arc Macro programming Language (AML) and C++ with an object-oriented structure. The grid was populated with an initial landscape strategy and forest unit attributes. The starting configuration was created on the basis of geographic data files derived from the forest management unit using ARC/INFO.

\section{Outputs}

The weights were respectively set at 0.4 for volume harvested and 0.6 for the old forest conservation. Simulation was performed on a Pentium(R) 4. The computation time was approximately four hours for 50 runs with up to 4000 iterations; each run had a different initial configuration. The number of iterations required for the algorithm to reach the highest possible average objective value was found to be between 2000 and 3000 iterations (Fig. 1). Beyond 3000 iterations, no noticeable improvement of the objective value was apparent. The variation in the objective function across runs is higher during the initial stages of the algorithm but progressively stabilizes (Fig. 1).

The improvement of the overall strategy seems to be prominently the result of an improvement in the harvest flow during initial iterations (Fig. 2). The irregular progression of the harvest flow in later iterations and its higher variability across runs (Fig. 2) compared to the objective function value in the same iterations (Fig. 1) both suggest that the clustering of old forest becomes more prominent in the later iterations.

The preference for old forest conservation is identical in all periods of the planning horizon, which seems to limit concentrating harvests to the first and final periods. However, the inclusion of external constraints or incentives would be necessary to ensure a more balanced flow of timber. Fig. 3 presents the old forest pattern of the area throughout planning periods. Old forest tends to be found in aggregate patches or in close proximity from each other.

\section{Discussion}

Validity of the results

As mentioned earlier, ecological processes and decision-making operates at a variety of scales and cell size may thus influ- ence the spatial patterns generated by CA. Chen and Mynett (2003) found that the principal spatial scale of the studied system is most appropriate to decide on CA cell size. A cell size of nine hectares was found to adequately represent the operations unit and stand polygons in the study area and was therefore chosen for this sample case. However, sensitivity analysis is required to verify the influence of size on the simulation output. A corollary implication of cell size influence is that it should be adjusted if this approach is applied to another area.

The cellular nature of the model makes it very portable for use in other forest regions. In addition to cell size, the cell states and the transition rules would also be adjusted to adequately reflect stand dynamics and decision options available in the area.

Its capability to include any state relevant to a forest management area and adapt transition rules to reflect the processes that influence forest changes in this area further allow the approach presented in this paper to be expanded to more realistic settings with the inclusion of economic objectives, stochastic processes (e.g., fire), and other decisions choices (e.g., selective logging). In terms of practical implementation, CA thus constitutes one means to integrate mathematical optimizations and search techniques with the experience and knowledge of experts. Its affinity with the raster models of geographical information systems also facilitates visualization of planning outcomes for public input.

\section{Appropriateness of the approach}

Most centralized and prescriptive methods developed in planning reflect the belief that humans can control the forest resource to produce the desired or optimal outcome. In contrast, contemporary knowledge points out that forests are complex co-evolutionary systems with changing functional controls in the ecosystem, in the economy and in the society (Berkes and Folke 1998, Holling et al. 1998, Ludwig 2001).

The cellular structure and the interdependence engendered from the transition rules imply that any specific element of the system reacts upon, and adjusts its behaviour in response to changes occurring in other elements. Therefore, all elements of the system are, in time, influenced by all changes in the system. A decentralized approach may not simplify the complexity associated with forest systems but it might better represent it. 


\section{Conclusion}

Although preliminary, the CA methodology developed in this paper shows that it is possible to simultaneously consider landscape level goals (harvest flow) and spatial goals (compact old forest reserves) with local decisions (stand scheduling). The simplistic CA evolving scheme presented in this paper showed that components from various spatial and temporal contexts can be integrated. This property makes it possible to directly integrate knowledge and metrics developed by experts from fields such as landscape ecology. The intertemporal "pre-cognition" of the evolving scheme and the ability to re-evaluate the plan in each time period makes it possible to model dynamic events such as catastrophes, market changes or dynamic preference parameters. Such a decentralized approach is potentially a good platform for modeling complex forest systems.

\section{Acknowledgements}

This work has been supported in part by a grant from the Sustainable Forest Management Network and an NSERC Research Grant. We are grateful to John Innes for his constant support and to David Tait for fruitful discussions and comments.

\section{References}

Agnoletti M. and S. Anderson (eds.). 2000. Methods and approaches in forest history. IUFRO Series No 3. CABI Publishing, Wallingford, UK. 281 p.

Ananda, J. and G. Herath. 2003. The use of the Analytic Hierarchy Process to incorporate stakeholder preferences into regional forest planning. Forest Policy Econ. 5(1): 13-26.

Bare, B.B., D.G. Briggs, J.P. Roise and G.F. Schreuder. 1984. A Survey of Systems Analysis Models in Forestry and the Forest Products Industries. Eur. J. Oper. Res. 18(1): 1-18.

Berkes F. and C. Folke (eds.). 1998. Linking Social and Ecological Systems: Management Practices and Social Mechanisms for Building Resilience. Cambridge University Press, Cambridge, UK,

Chen, Q. and A.E. Mynett. 2003. Effects of cell size and configuration in cellular automata based prey-predator modelling. 11(7-8): 609-625.

Clawson, M. 1975. Forests for whom and for what? John Hopkins University Press, Baltimore and London. 175 p.

Cohen, D.H. and R.A. Kozak. 2002. Research and Technology: Market Driven Innovation in the Twenty-First Century. For. Chron. 78(1): 108-111.

Davis L.S., K.N. Johnson, P.S. Bettinger and T.E. Howard (eds.). 2001. Forest Management. Fourth Edition. McGraw-Hill, New York. $804 \mathrm{p}$.

Fiedler P.L. and P.M. Kareiva (eds.). 1998. Conservation biology for the coming decade. Second Edition. Chapman and Hall, New York. $553 \mathrm{p}$.

Holling, C.S., F. Berkes and Folke C. 1998. Science, sustainability and resource management. In F. Berkes and C. Folke (eds.). Linking Social and Ecological Systems. pp. 342-362. Cambridge University Press, Cambridge, UK.

Jacobs, M. 1991. The Green Economy: Environment, Sustainable Development and the Politics of the Future. Pluto Press, London. $312 \mathrm{p}$.

Kant, S. 2003. Extending the boundaries of forest economics. Forest Policy Econ. 5(1): 39-56.

Ludwig, D. 2001. The era of management is over. Ecosystems 4: 758-764.

Martell, D.L., E.A. Gunn and A. Weintraub. 1998. Forest management challenges for operational researchers. Eur. J. Oper. Res. 104(1): $1-17$.
McDill, M.E. 1992. Linking strategic, tactical, and operational forest planning techniques: Opportunities and problems in Minnesota. In Proceedings of the Society of American Foresters National Convention. October 25-27 1992, Richmond, Virginia., pp. 376-381. The Society, Bethesda, MD.

Meffe, G.K., C.R. Carroll and contributors. 1997. Principles of Conservation Biology. Second Edition. Sinauer Associates Inc., Sunderland, Massachusetts. 729 p.

Nelson, J.D. 2003. Forest-level models and challenges for their successful application. Can. J. Forest. Res. 33: 422-429.

Oliver, C.D. 1999. The future of the forest management industry: highly mechanized plantations and reserves or a knowledge-intensive integrated approach. For. Chron. 75(2): 229-245.

Porter, M.E. and R.L. Martin. 2000. Canadian Competitiveness: Nine Years after the Crossroads. Paper presented at the CSLS Conference on the Canada - U.S. Manufacturing Productivity Gap. Ottawa. 30 p.

Reed, F.L.C. 2000. Is enhanced forestry worth the investment? Getting the analytical framework right. Available at http://www.wsca.ca/Media/Multimedia/Les\%20Reed.htm

Schwartz, M.W. 1999. Choosing the appropriate scale of reserves for conservation. Annu. Rev. Ecol. Syst. 30: 83-108.

Shafer, C.L. 2001. Inter-reserve distance. Biol. Conserv. 100(2): 215-227.

Sheppard, S.R.J., P. Picard and R. D'Eon. 2004. Meeting visual quality objectives with operational radial-strip partial cutting in coastal British Columbia: a post-harvest assessment. For. Chron. 80(2): 215-223.

Sherry, E.E. and C.J. Johnson. 1999. The forgotten forest: Revisiting the forestland allocation strategy. For. Chron. 75(6): 919-927.

Shindler, B.A., M. Brunson and G.H. Stankey. 2002. Social acceptability of forest conditions and management practices: a problem analysis. Gen. Tech. Rep. PNW-GTR-537. U.S. Department of Agriculture, Forest Service, Pacific Northwest Research Station, Portland, OR. 68 p.

Stankey, G.H. and R.N. Clark. 1992. Social aspects of new perspectives in forestry: a problem analysis. Grey Towers Press, Milford, PA. $33 \mathrm{p}$.

Stewart, T.J., R. Janssen and M. van Herwijnen. 2004. A genetic algorithm approach to multiobjective land use planning. Comput. Oper. Res. 31(14): 2293-2313.

Strange, N., H. Meilby and B.J. Thorsen. 2002. Optimization of land use in afforestation areas using evolutionary self-organization. For. Sci. 48(3): 543-555.

Toffoli, T. and N. Margolus. 1987. Cellular Automata Machines. MIT Press, Cambridge, MA. 200 p.

United Nations Conference on Environment and Development (UNCED). 1992. Agenda 21: The Rio Declaration on Environment and Development, the Statement of Forest Principles, the United Nations Framework Convention on Climate Change and the United Nations Convention on Biological Diversity. UNCED, Rio de Janeiro, 3-14 June 1992. United Nations Commission on Environment and Development Secretariat, Geneva.

Venema, H., P. Calamai and P. Fieguth. 2005. Forest structure optimization using evolutionary programming and landscape ecology metrics. Eur. J. For. Oper. Res. 164: 423-439.

Voller J. and S. Harrison (eds.). 1998. Conservation biology. Principles for forested landscapes. Second Edition. UBC Press, Vancouver. $256 \mathrm{p}$.

Weintraub, A. and B.B. Bare. 1996. New issues in forest land management from an operations research perspective. Interfaces 26(5): 9-25.

Weintraub, A. and A. Cholaky. 1991. A hierarchical approach to forest planning. For. Sci. 37(2): 439-460. 